https://doi.org/10.23913/ride.v11i22.867

Artículos científicos

\title{
Análisis del aspecto educativo-artístico de Claudio Vásquez a través de la psicología del color en once pinturas de su creación en el periodo de 1987 a 1994
}

\begin{abstract}
Analysis of the artistic educational aspect of Claudio Vásquez through the psychology of color in 11 paints of its creation in the period from 1987 to
\end{abstract}

1994

Análise da vertente educacional-artística de Claudio Vásquez através da psicologia da cor em onze pinturas de sua criação no período de 1987 a

1994

Claudio Rafael Vásquez Martínez

Universidad de Guadalajara, México crvasquezm@gmail.com https://orcid.org/0000-0001-6383-270X

Felipe Anastacio González González

Universidad Autónoma de Tamaulipas, México

felgonzale@docentes.uat.edu.mx https://orcid.org/0000-0002-1410-8616

\section{Resumen}

El objeto de esta investigación fue analizar — con base en la psicología del color-el aspecto educativo-artístico de 11 pinturas creadas por Claudio Vásquez entre 1987 y 1994. Para cumplir con este objetivo, en primera instancia, se aplicaron elementos del test de Lüscher (1982) a cada una de las pinturas para después generar un análisis y una conclusión. Esta investigación procuró descubrir el qué de las situaciones, ya que se utilizó la técnica de análisis para determinar un objeto de exploración o una situación concreta para señalar sus características y propiedades. Como conclusión se puede indicar que en las obras estudiadas 


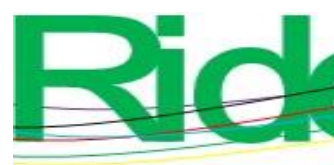

Revista Iberoamericana para la
Investigación y el Desarrollo Educativo
ISSN $2007-7467$

sobresalen los colores verde y azul, lo que muestra aspectos educativos de Claudio Vásquez que se asocian con una adecuada sensibilidad y comprensión, lo cual influye en una autoestima alta. Asimismo, tiende a buscar cosas nuevas que le den satisfacción, pero que no traigan consigo incomodidad o perturbación en lo corporal.

Palabras clave: creación, educativo, psicología del color.

\section{Abstract}

The purpose of this research was to analyze - based on the psychology of color - the educational-artistic aspect of 11 paintings created by Claudio Vásquez between 1987 and 1994. To meet this objective, in the first instance, elements of the Lüscher test were applied (1982) to each of the paintings to later generate an analysis and a conclusion. This investigation tried to discover the what of the situations, since the analysis technique was used to determine an object of exploration or a concrete situation to indicate its characteristics and properties. As a conclusion, it can be indicated that green and blue colors stand out in the works studied, which shows educational aspects of Claudio Vásquez that are associated with adequate sensitivity and understanding, which influences high selfesteem. Also, he tends to look for new things that give him satisfaction, but that do not bring discomfort or disturbance in the body.

Keywords: creation, educational, psychology of color.

\section{Resumo}

O objetivo desta pesquisa foi analisar - com base na psicologia da cor - o aspecto artísticoeducacional de 11 pinturas realizadas por Claudio Vásquez entre 1987 e 1994. Para atender a esse objetivo, em primeira instância, foram aplicados elementos do teste de Lüscher (1982) a cada uma das pinturas para posteriormente gerar uma análise e uma conclusão. Esta pesquisa buscou descobrir o quê das situações, uma vez que a técnica de análise foi utilizada para determinar um objeto de exploração ou uma situação específica para indicar suas características e propriedades. Como conclusão, pode-se apontar que as cores verde e azul se destacam nas obras estudadas, o que mostra aspectos educacionais de Claudio Vásquez que estão associados à sensibilidade e compreensão adequadas, que influenciam na alta 


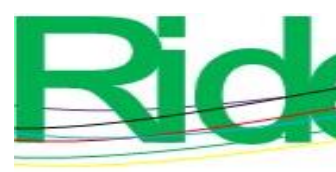

Revista Iberoamericana para la

Investigación y el Desarrollo Educativo

ISSN $2007-7467$

autoestima. Além disso, você tende a procurar coisas novas que lhe dêem satisfação, mas que não tragam desconforto ou perturbação para o corpo.

Palavras-chave: criação, educacional, psicologia da cor.

Fecha Recepción: Junio 2020

Fecha Aceptación: Febrero 2021

\section{Introducción}

El arte en sus distintas manifestaciones (pintura, poesía, literatura, etc.) es una forma de simbolización que usa el ser humano no solo para intentar generar en los espectadores una diversidad de emociones, sino también para expresar sus pensamientos, de ahí que el análisis de las obras de un artista sea un procedimiento valioso para procurar descifrar su personalidad, sus temores, sus dudas, sus ilusiones y, en definitiva, su manera de concebir el mundo (Jiménez, 2002).

Por ese motivo, el presente trabajo se ha enfocado en el análisis - mediante la psicología del color - de once pinturas de Claudio Rafael Vásquez Martínez con el fin de descubrir su aporte educativo-artístico. La naturaleza del color es un área que se centra en examinar el resultado de las diferentes tonalidades de la luz y el color para conocer su vínculo con los acontecimientos psíquicos que pueden generar. En palabras de Gómez (2016), se puede afirmar que el ser humano se ve influenciado tanto de manera positiva como negativa por la forma física, psicológica y emocional de los colores que ve a su alrededor (Gómez, 2016).

Asimismo, vale señalar que en la creación artística es preciso trascender los patrones convencionales para encontrar diferentes sentidos que se sustentan en la variedad y en la cantidad de ideas nuevas (Botetano, 2014). Esto sucede porque el resultado del proceso artístico no consiste solo en la búsqueda del placer mediante formas de expresión, sino que también se consolida en la transmisión de información a través de metodologías que logran convertirse en conocimiento. Es decir, lo abstracto, lo concreto y las diferentes técnicas usadas por el artista pueden producir en el espectador nuevas y variadas realidades. Esto permite comprender al artista como un ser que busca la libertad de expresión, la verdad y las realidades del conocimiento a través de la educación visual.

Claudio Rafael Vásquez Martínez nació el 22 de mayo de 1957 en la ciudad de Marinilla, Antioquia (República de Colombia), donde vivió hasta 1987. En 1988 se radicó en México debido a los conflictos políticos y sociales de su país, donde en medio de una 


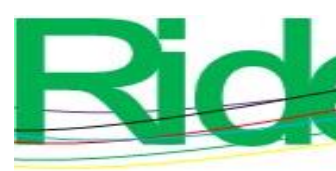

Revista Iberoamericana para la Investigación y el Desarrollo Educativo ISSN $2007-7467$

guerra sin fin de guerrillas y narcotráfico varios de sus colegas fueron asesinados por adoptar una posición crítica frente los crímenes cometidos por la narcoguerrilla (Benítez, 2009).

Su obra pictórica está constituida por paisajes terapéuticos — creados al óleo y en acuarela - que invitan a la serenidad, la tranquilidad y el rescate ecológico (Reyes, 2006; Vásquez, 11 de enero de 2000). Este autor, de hecho, considera a la pintura como filosofía de vida que desarrolla mediante nuevos códigos psicológicos (Gómez, 2006) para que la gente se dé cuenta de la importancia de conservar la ecología (Vásquez, 2 de febrero de 2008). Esta concepción de la vida fue inspirada por el pensamiento de Frankl (1991) y su visión positiva ante las adversidades.

Su filosofía e inspiración, por tanto, se enfocan en intentar dejar un legado a las futuras generaciones de materiales registrables con visión positiva, los cuales se encuentran en las bibliotecas de la Universidad de Guadalajara, del Congreso de Estados Unidos de América y del Banco de la República de Colombia en Bogotá.

Claudio Vásquez es licenciado en educación por la Universidad de San Buenaventura (1981); asimismo, cuenta con una maestría y un doctorado en educación, así como otros postgrados en relaciones industriales y matemáticas (Vásquez, 1999). Además, es maestro distinguido con el título honoris causa por la Universidad de Bamberg (Alemania).

Es profesor en los cinco continentes sobre pintura y educación. De hecho, ha sido asesor universitario en Australia, Inglaterra, Alemania, China, Japón, Corea, Finlandia, Estados Unidos de América y Sudáfrica. Ha realizado importantes contribuciones en la rama de educación a distancia, y ha viajado por los cinco continentes para estudiar la metodología de la pintura (Ortiz, 2004).

Realiza una exposición permanente de 531 pinturas en la Editorial Papiro y desde 2001 hasta la actualidad es profesor investigador titular C del Centro Universitario de la Costa en Puerto Vallarta, donde también es coordinador del taller de pintura educativa. Ha publicado más de 150 libros sobre pintura paisajista y ha creado más de 500 obras (Rodríguez, 20 de diciembre de 2017). 


\section{Marco teórico}

Foucault (2017) explica que "el discurso y la forma se desplazan uno en relación al otro. Además, observa que en el discurso y la figura tienen cada uno su modo de ser propio; pero mantienen relaciones complejas y encabalgadas" (p. 2). Por ello, se puede señalar que la disciplina artística es una de las expresiones más trascendentales de la vida del ser humano, ya que puede funcionar como un eje principal en la mejora y en el progreso del individuo a través del cual se manifiesta una perspectiva propia y proactiva que demuestra lo existente o irreal con distintas técnicas sonoras, plásticas o lingüísticas (Adorno, 2004). Es, por ende, "una respuesta a la vida. Ser artista es emprender una manera riesgosa de vivir, es adoptar una de las mayores formas de libertad, es no hacer concesiones. En cuanto a la pintura, es una forma de amor, de transmitir los años en arte" (Berni, 1971, p. 5).

En efecto, con la pintura se puede plasmar una visión del arte y del mundo donde cada artista proyecta su propia esencia gracias a su técnica y estilo propio. De este modo, intenta trascender sin decir una sola palabra, pues el lienzo funge como un mecanismo discursivo que invita a reflexionar y a analizar el mundo desde otra perspectiva (García Morales, 2012).

Uno de los estilos que genera impacto en la sociedad es el imaginativo, el cual se enfoca generalmente en los problemas sociales actuales relacionados, por ejemplo, con lo educativo, área en la cual se promueve el pensamiento lógico, aunque a veces se deja de lado la creatividad, la imaginación, la curiosidad y la empatía, elementos esenciales para potenciar algunos talentos. Por eso, se considera que las disciplinas artísticas constituyen una excelente estrategia para activar el hemisferio derecho del cerebro (Botetano, 2014), lo que permite vincular a los sentimientos con la reflexión, acción significativa que se convierte en un aliado estratégico de lo educativo (Cotes, 27 de enero de 2018).

En este contexto, la pintura educativa es entendida como un recurso didáctico que sirve para fomentar en la persona una pedagogía emancipadora, pues funciona como retroalimentación para crear una nueva forma de conocimiento y aprendizaje significativo. Ese mensaje que trae consigo la obra se percibe de manera subjetiva según el receptor, de ahí que la respuesta y el aprendizaje generados sean diferentes en cada caso.

Los colores juegan un papel importante en esta variedad de percepciones, ya que los gustos o las aficiones de cada persona determinarán las sensaciones o emociones que se generen en ella. De acuerdo con Cotes (27 de enero de 2018), se cree que la mayoría de las 


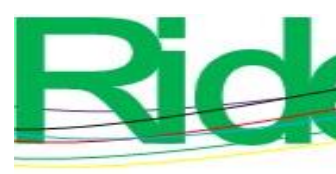

Revista Iberoamericana para la Investigación y el Desarrollo Educativo ISSN $2007-7467$

personas tienen afinidad por ciertos colores debido a que buscan a través de ellos reacciones que se generan de manera inconsciente. Esto mismo sucede con el artista, quien en sus obras proyecta sus estados de ánimo, sus ideales, etc.

La intención, por tanto, es un elemento fundamental en la pintura, ya que orienta los trazos que marca el pincel sobre un lienzo para provocar una primera impresión teñida por la emoción, la cual no sería posible sin la sensibilidad que posee cada receptor. Así, la disciplina artística nace de la pasión y regresa transformada en obras. Este proceso logra después espacios sociales, sistemáticas o particulares. La pasión tiene la característica de concretarse en dos clases de acciones: las estéticas y/o artísticas, de las cuales las primeras son necesarias. Es por lo anterior que ninguna pasión puede eludir el compromiso de adentrarse en la belleza y en demás cualidades estéticas del entorno, donde a la vez lo estético implica lo artístico, aunque igualmente ocurre en sentido contrario, ya que es muy común que lo artístico abarque lo estético, así como otras cosas más. Uno es parte del otro, pero ni todo es arte ni estético aunque se presente como arte (Acha, 1988).

El resultado del arte, entonces, demanda diferentes interpretaciones, las cuales se sustentan no solo en un razonamiento basado en la imaginación, sino también en un bagaje acerca de las obras, pues el objetivo es hallar interpretaciones a partir del punto de vista particular del observante y del contexto de esa obra.

Así surge esta necesidad de interpretar las obras, eje de la confusa y extensa manifestación cultural artística que intenta servir de engrane principal entre el objeto y el sujeto que da forma a esta realidad. En la concepción personal se centra la conceptualización sensorial a través del arte observado, es decir, el consumo de las artes visuales (Acha, 1988).

Solo falta prestar atención a las pinturas para demonstrar que los códigos de su significado son innecesarios a la hora de revelar cómo la obra logra poner al individuo en contacto con un mundo interior. Ambiciones, sentimientos, ilusiones y certezas son el elemento que anima a las obras de arte. Sin lo mencionado anteriormente, lo sombrío y caprichoso de los estados mentales no cabría en las obras de pintura, conceptualizadas como arte, y no habría expresión alguna que el observador pudiera recibir (Pérez, 1997).

En otras palabras, el resultado del proceso artístico no es solo útil para el placer y para las formas de expresión, pues también se consolida en la transmisión de información que a través de metodologías pedagógicas logra convertirse en conocimiento. Lo abstracto, lo concreto y las diferentes técnicas usadas por el artista pueden dar pauta a múltiples 


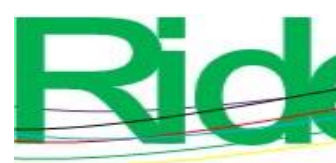

Revista Iberoamericana para la

Investigación y el Desarrollo Educativo

ISSN $2007-7467$

realidades que evocan en el observante nuevas y variadas realidades para comprender cada obra, lo que da inicio a la creación de verdades absolutas o relativas.

La pintura es universal y los colores plasmados entretejen el precepto de multidisciplinar. Esto sirve de apoyo para entender al artista como un ser que busca la libertad de expresión, la verdad y las realidades del conocimiento a través de la educación visual. Además, como lo propone Acha (1988), existe la necesidad de reinventar gradualmente la educación a través del arte. Por ello, resulta significativo comprender la obra del artista seleccionado en este estudio, pues los aportes conseguidos influirán en gran medida en esta reinvención que es prioritaria; en este caso, desde la pintura.

Sustentar que las pinturas expresan sentimientos no implica un estado emocional único del artista, sin embargo, se defiende el emotivismo estético sin una explicación de tipo estímulo-respuesta, ni la necesidad de que el artista se encuentre en un estado de ansiedad o tristeza cuando plasma estas emociones, aunque solo a quien puede rescatar esas emociones frente a un cuadro le está permitido entenderlo.

Si bien muchas pinturas pueden apreciarse por lo que son, el disfrute de ellas puede verse intensificado si se perfecciona la destreza visual. Los artistas pintan porque se sienten complacidos con ello, y se inspiran para establecer analogías con el mundo que los rodea (Rideal, 2014). Es importante mencionar que en su gran mayoría las pinturas no ejercen el mismo impacto o nivel de asombro, ni todos los observadores disponen de un sentido interpretativo.

Todo esto depende de la capacidad de percepción, la cual se desarrolla a través del hemisferio derecho del cerebro. Al respecto, vale destacar que cada mitad del cerebro procesa la información que absorbe de diferente forma, de ahí que existan distintas maneras de pensamiento agrupadas con cada hemisferio. Por ejemplo, en la parte lógica - que corresponde al izquierdo (HI) — se procesa la información de modo secuencial y lineal, mientras que en el hemisferio derecho (HD) se hace de manera holística, partiendo del todo para concebir los diferentes fragmentos que lo componen. El hemisferio holístico es automático — no lógico - y trabaja con esquemas y emociones. Este emplea una forma de pensamiento contrario, discrepante en todo momento, que crea una diversidad y un gran número de ideas nuevas que trascienden los esquemas supuestos (Botetano, 2014), de ahí la importancia de estimular desde temprana edad la parte derecha del cerebro. 


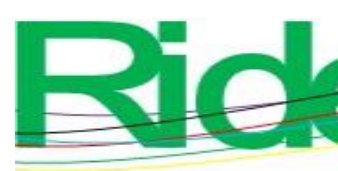

Revista Iberoamericana para la

Investigación y el Desarrollo Educativo

ISSN $2007-7467$

Los niños no nacen con conocimiento; cada individuo en su edad temprana tiene que desarrollar asiduamente sus propias maneras de comprensión y generar nuevos conocimientos con el paso del tiempo, de modo que cada acción temporal o conjetura representan en cada momento su deseo de dar sentido al mundo (Gardner, 1993).

El arte es un lenguaje visual, no de palabras. Por eso, las conclusiones que se basan en una comunicación verbal o escrita suponen un paralelo, pero no una verdadera equivalencia. "El arte se crea para el ojo; con palabras solo puede sugerirse" (Baldessari, 2013, p. 16). El artista conceptual Marcel Duchamp sostenía que la existencia de una obra de arte depende tanto del artista como del espectador. La belleza del arte está en la mirada de quien lo observa. De hecho, pensar y contemplar arte suele ser gratis, y puede resultar muy satisfactorio y gratificante (Rideal, 2014).

\section{Propuesta teórica: psicológica del color según Max Lüscher}

Lüscher (1982) indica que en el mundo artístico se observan cuatro colores psicológicos primarios, los cuales se dividen en dos grupos: heterónomos y autónomos. Los primeros hacen referencia al azul y al amarillo, mientras que los segundos al rojo y al verde, que simbolizan la acción y la polémica, así como la protección de la entidad. El rojo como acción externa dirigida a tomar y obtener, y el verde como instinto de conservación para defenderse de las agresiones y subsistir. Tanto la defensa (verde) como el ataque (rojo) están controlados por el individuo, y se llaman colores autónomos o autorregulados.

El test de los colores de Lüscher (1982) ha sido muy utilizado por su fácil aplicación y su robusta estructura en el estudio de la personalidad; fue creado por Max Lüscher, y su principal característica es la elección cromática como indicador de las facciones de personalidad. El instrumento consiste en presentar al evaluado una gama de colores ante los cuales debe mostrar su favoritismo. De esta forma, la inclinación de un color y el rechazo de otros representan algo muy concluyente, pues manifiestan un estado mental, de equilibrio glandular o bien las dos cosas.

Asimismo, es importante resaltar las dos verdades de la teoría cromática de Lüscher (1982): a) cada tonalidad tiene su propio significado sociopsicofisiológico autónomo de elementos culturales y temporales, y b) cada individuo actúa de manera subjetiva al ver un color en su medioambiente (Aguirre, 2006). 


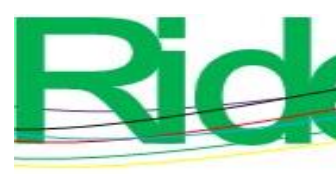

Revista Iberoamericana para la Investigación y el Desarrollo Educativo ISSN $2007-7467$

La prueba completa de Lüscher brinda la oportunidad de conocer el contexto de la persona en su diversa interacción entre alma y cuerpo, haciendo hincapié en la dinámica de su carácter, los procesos de frustración y de resiliencia, el estado somático, las áreas de tensiones y lo que da a lugar el observar las áreas de "peligro" antes de la histeria crónica (Miño, 2011). Bustos y Devoto (2008) describen el significado de cada uno de los colores retomando a Lüscher.

\section{Gama de colores principales de Lüscher}

- Azul (1): Se relaciona con la etapa oral. Simboliza los vínculos intrínsecos, la integración y el sentimiento de pertenecer a un grupo social. También se vincula con el ser proactivo, la concentración, el descanso y la regeneración. En un grado de importancia alto, implica retroceso, inactividad y dependencia psicológica. Si es expulsado, impulsa el deseo de cortar los lazos, falta de voluntad y difícil concentración.

- Verde (2): Este color corresponde a la etapa anal y a la conceptualización de la realidad. Es la voz del yo, de la autoestima y la importancia de moralidad. También corresponde a la constancia, la restricción y la resistencia al cambio. Si su inclinación a este color es alta, indica rigidez, rigurosidad moral, egocentrismo y presunción. Si es rechazado, es índice de inseguridad y dificultad para ser constante.

- Rojo (3): Tiene un efecto alentador en el sistema simpático. Se relaciona con la etapa genital y el principio del gozo. Es la energía vital y la libido. Se vincula con el entusiasmo y el deseo en todo ámbito. Se asocia al impulso, la sexualidad y la competitividad. Si su inclinación a este color es alta, resulta en impulsividad, entusiasmo y provocación. Cuando es separado de un grupo social, indica abstención del deseo e impotencia física.

- Amarillo (4): Este color principalmente se relaciona con el contorno visual; representa la utopía y lo absurdo. Corresponde con la liberación de las preocupaciones, aumenta el alivio y la alegría. La inclinación a esta tonalidad indica el deseo de descanso, de esperanza en un cambio y corrección del futuro. En su alta preferencia, involucra un deseo de escape junto a una actitud frívola y una habilidad inmadura al cambio. Si el sujeto es rechazado, implica desilusión, falta de confianza y suspicacia hacia su vida social. 


\section{Los colores complementarios de Lüscher}

- Violeta (5): En cuanto a lo sociopsicológico, implica cambios en las emociones y persuasión por parte del sujeto. Corresponde con la evolución y la transformación. Frecuentemente es catalogado como color favorito de homosexuales, preadolescentes, personas inmaduras, infantiles o con bajo nivel cognitivo. Su mayor preponderancia sobre los colores fundamentales se vincula con facilidad de ser influenciado o directamente con rasgos irritables.

- Café (6): Se refiere a la escasez de dicha, por lo que (en cierta medida) es un color contraproducente. Cuando es preferido, siempre indica estrés y necesidad consciente de recuperar energía. Si es separado de un grupo social, revela dificultad para satisfacer las insuficiencias corporales. Es un mundo irreal; este color debe ser indiferente para el sujeto, pues una persona sana no prestaría atención especial a su cuerpo.

- Negro (7): Respecto a lo sociopsicológico, involucra obsesión, oposición, rechazo y terquedad agresora. Idealmente, debe ser rechazado. Si es el color favorito, las tonalidades que lo anteceden pierden parcialmente su significado estructural. Es un color que suele poner nervioso de manera muy negativa a las características funcionales del color que acompaña.

- Gris (8): En su significado psicológico involucra protección ante la involucración y la reflexión; la persona pone una barrera entre sí y su vida interior, y entre esta y el mundo. Tiene un carácter autoprotector. Involucra distanciamiento, bloqueo, enmascaramiento como defensa y evitación del vínculo afectivo. Si es el color preferido, indica agotamiento y tendencia psicosomática.

- Blanco (9): Similar al amarillo, implica desbloqueo de tensiones y consuelo en el plano funcional corporal, pero de manera más acentuada. En el plano mental, implica grandes deseos de independencia, escape y renovación en quienes lo eligen. 


\section{Objeto de estudio}

El objeto de esta investigación fue analizar - con base en la psicología del colorel aspecto educativo-artístico de 11 pinturas creadas por Claudio Vásquez entre 1987 y 1994. Las obras fueron las siguientes: Montañas y lago (1987), Anochecer (1988), Atardecer (1988), Volcán (1989), Montañas (1989), Montañas (1989bis), Montañas (1990) Cactus (1991), Atardecer (1992), y Amanecer (1992), Montañas (1994).

Para cumplir con este objetivo, se retomaron elementos del test de Lüscher como base para analizar las referidas obras. En primera instancia, se aplicaron elementos del test de Lüscher (1982) a cada una de las pinturas para después generar un análisis y una conclusión.

Esta es una investigación que procura descubrir el qué de las situaciones, ya que utiliza la técnica de análisis para determinar un objeto de exploración o una situación concreta para señalar sus características y propiedades.

\section{Marco analítico}

Figura 1. Montañas y lago (1987)

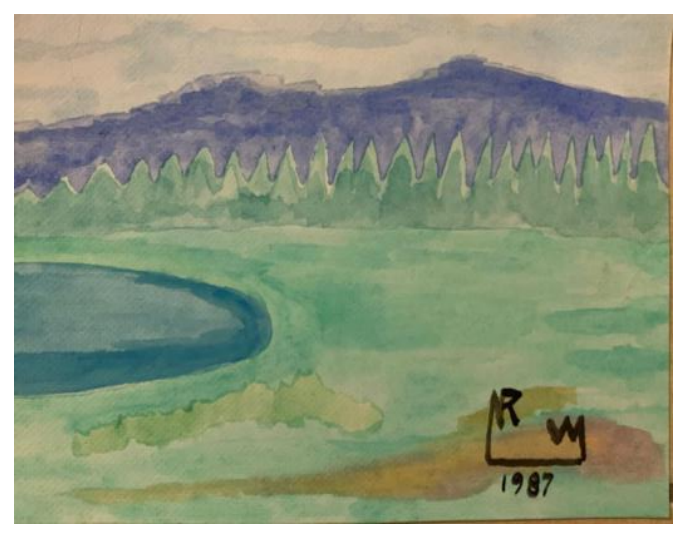

Fuente: Elaboración propia

En esta obra están presentes los colores verde, azul, blanco, amarillo y café. En primer lugar, la combinación del azul y el verde puede significar, según Lüscher, sensibilidad y comprensión, las cuales se encaminan a un aumento de la autoestima, incitando orden y método. La combinación amarillo-café indica que la persona requiere satisfacción física y encontrarse independiente de todo tipo de dificultad o temor que le 


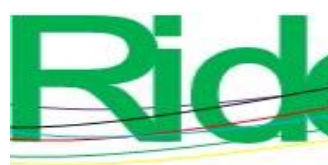

Revista Iberoamericana para la Investigación y el Desarrollo Educativo ISSN 2007-7467

produzca incertidumbre; por último, el blanco refleja anhelo de libertad, escape y renovación.

Figura 2. Anochecer (1988)

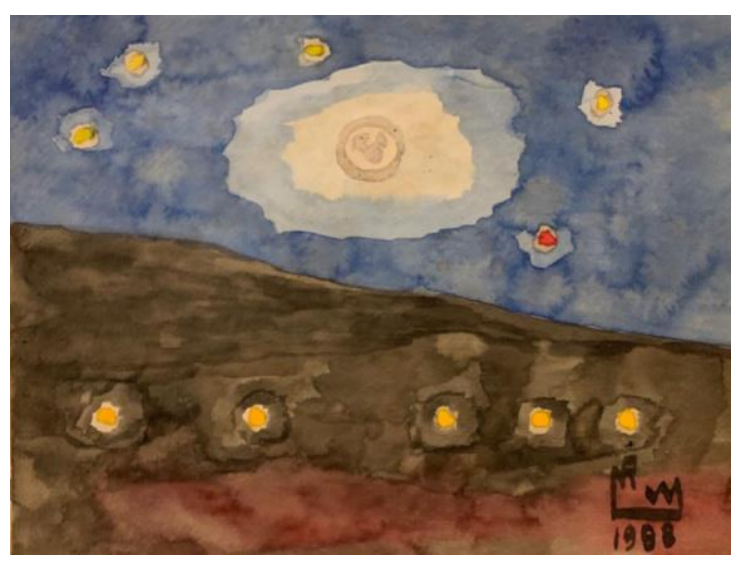

Fuente: Elaboración propia

Los colores utilizados en esta segunda obra son el azul, el café, el amarillo, el rojo y el blanco. Así pues, se tiene que la combinación del azul y el café indican un bienestar sensual o vínculo indolente. El amarillo y el rojo en combinación pueden significar una actividad expansiva o el desarrollo de nuevos campos, es decir, se busca lo nuevo y lo que dé satisfacción. El blanco hace alusión a la liberación de tensiones y el consuelo en el plano fisiológico.

Figura 3. Atardecer (1988)

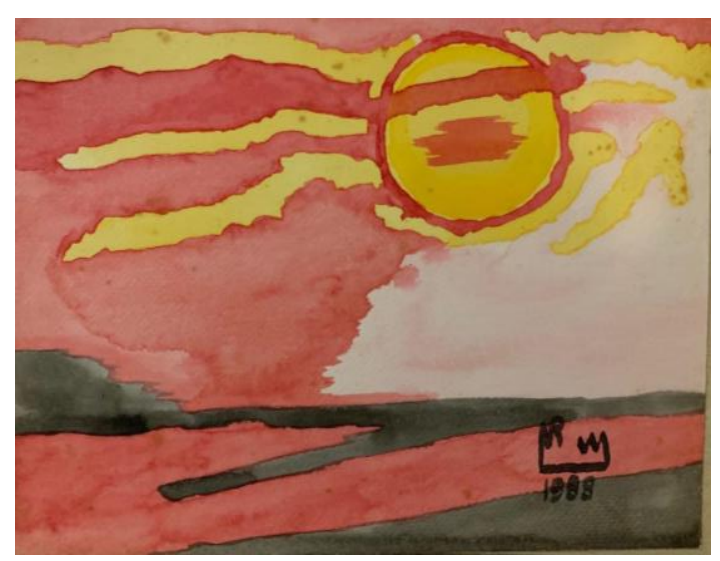

Fuente: Elaboración propia 

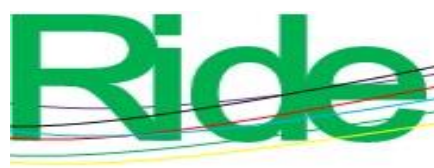

Revista Iberoamericana para la Investigación y el Desarrollo Educativo

ISSN $2007-7467$

En esta tercera pintura el color predominante es el rojo, el cual está presente junto al café y el amarillo. En tal sentido, la combinación del rojo y el café muestran una satisfacción sensual o desenfreno, lo que quiere decir que la realización de las actividades se limita al hecho de que el cuerpo no debe ser perturbado ni incomodado de ningún modo. Por otro lado, la combinación del rojo y el amarillo denotan una actividad expansiva, es el agrado de hacer la misma tarea, siempre encaminada hacia lo desconocido, hacia todo aquello que aún está por manifestarse.

Figura 4. Volcán (1989)

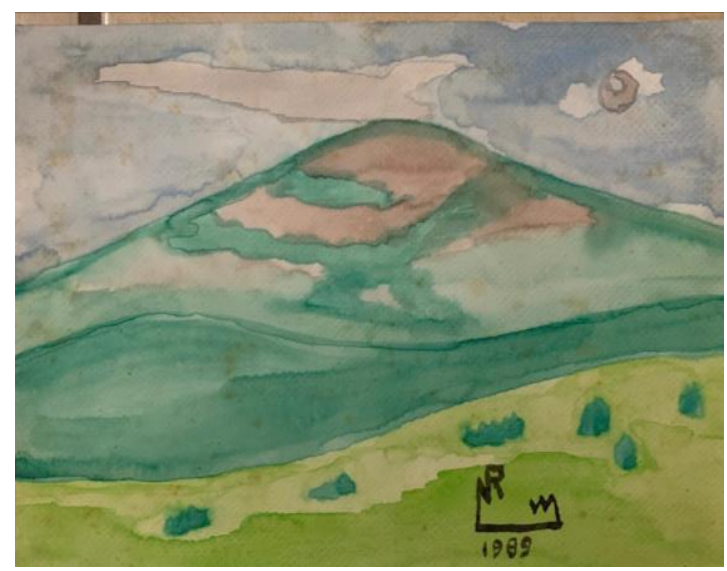

Fuente: Elaboración propia

El color predominante de esta pintura es el verde, tanto en un tono intenso como en un tono leve. Asimismo, se hallan presentes el gris y el azul. Así, la combinación del verde y el gris pueden indicar una superioridad defensiva, ya que la autoestima, la intensión de impresionar y el pensamiento de prestigio se engrandecen; por otro lado, la combinación del verde y el azul hacen referencia a un control discriminativo. Así, la puntualidad, la razón y la necesidad de manifestar que se está en lo cierto toman preponderancia sobre la comprensión, el precepto y el procedimiento, que están más orientados al aumento de la autoestima. 

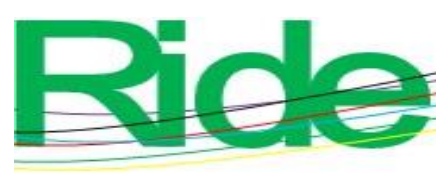

Revista Iberoamericana para la Investigación y el Desarrollo Educativo

Figura 5. Montañas (1989)

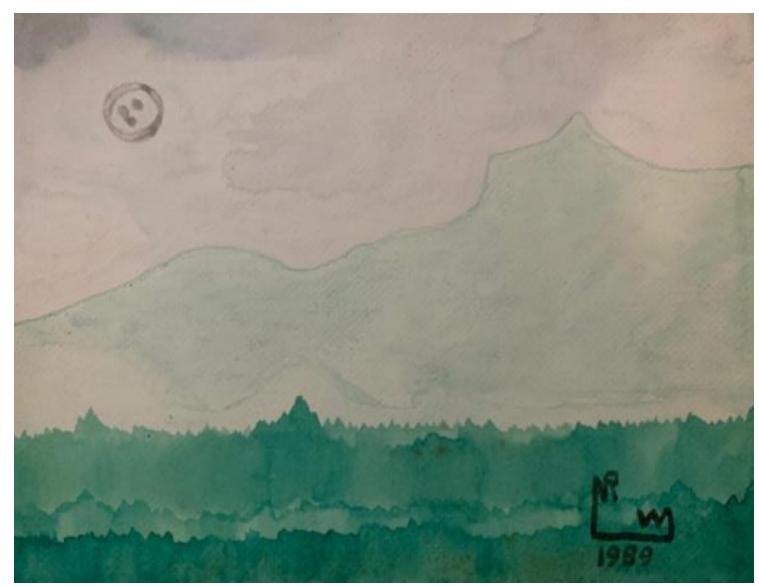

Fuente: Elaboración propia

En esta obra se encuentran presentes los colores verdes (en el bosque y en la montaña), así como el gris (en el cielo y en la luna). La combinación del verde y el gris puede indicar una autorrealización superativa o supremacía defensiva, donde la autoestima, junto con la necesidad de impresionar y el conocimiento de prestigio, se engrandecen.

Figura 6. Montañas (1989bis)

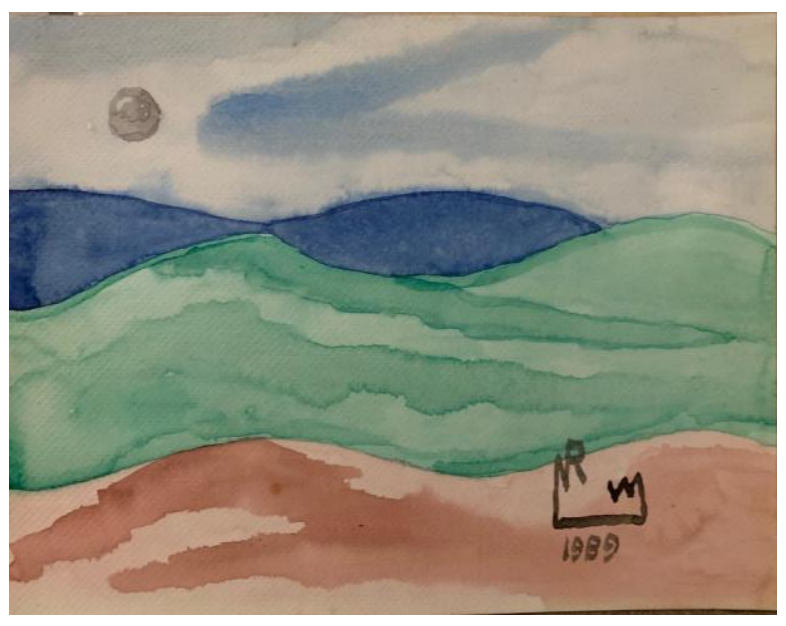

Fuente: Elaboración propia

Los colores que se pueden observar en esta pintura son el azul, el verde, el café y el gris; por lo tanto, la combinación del azul (montañas y cielo) con el gris (luna) dan como resultado lo que puede ser un momento de calma o espacio de liberación. La combinación del color verde y el café hacen alusión al requerimiento de descanso corporal o búsqueda de la comodidad, lo cual quiere decir que el yo puede prolongarse cuidándose a sí mismo solo si se encuentra libre de circunstancias que le causen malestar. 


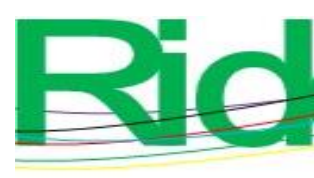

Figura 7. Montañas (1990)

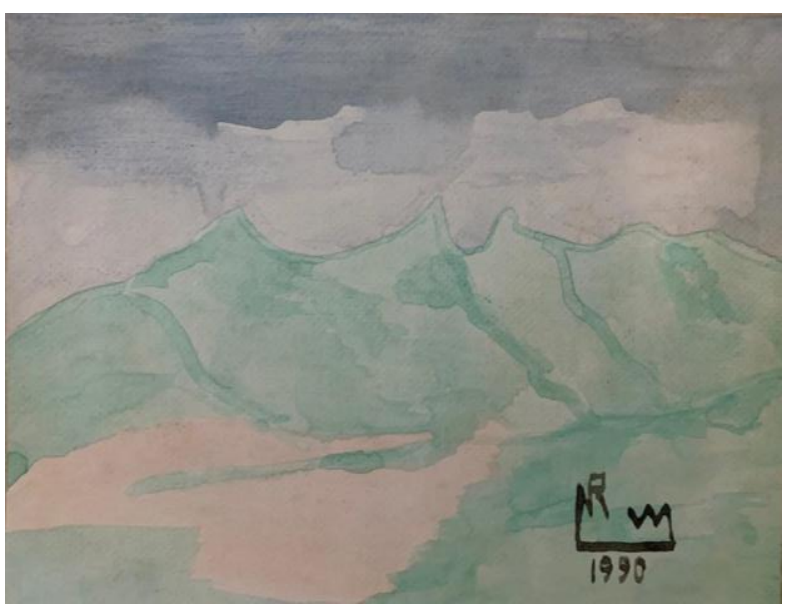

Fuente: Elaboración propia

El color que predomina en esta pintura es el verde (montañas), seguido del gris (cielo) y un tono café claro (tierra entre las montañas). En este caso, la combinación del verde y el café sugiere un requerimiento de descanso físico o la insistencia en el bienestar; asimismo, la combinación del verde y el gris puede referirse a una autorrealización separativa o supremacía defensiva.

Figura 8. Cactus (1991)

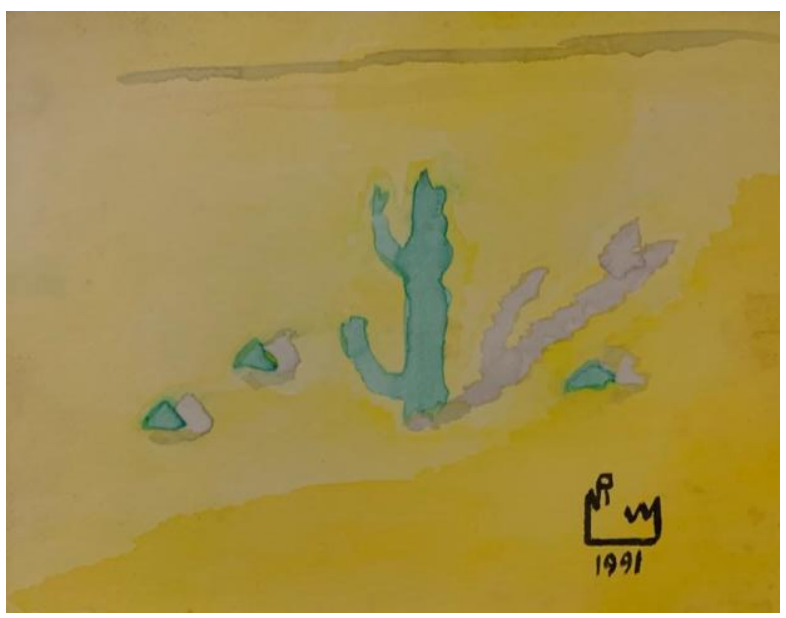

Fuente: Elaboración propia

En esta obra sobresale el color amarillo, que abarca gran parte de la pintura (desierto), así como el verde (en el cactus) y el café (en las sombras). La combinación del amarillo y el verde dan como resultado una exigencia de valoración o ambición; en este caso, la ambición se muestra como una ilusión de que manteniéndose alerta y observante se abrirán nuevos caminos que permitirán lograr el reconocimiento necesario; por otra parte, la combinación 


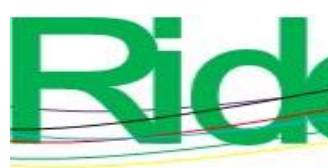

Revista Iberoamericana para la Investigación y el Desarrollo Educativo ISSN $2007-7467$

del amarillo y el café denota seguridad social o bienestar sin obstáculos. Aquí la resolución precisa bienestar físico y estar libre de cualquier dificultad o desconfianza que produzca inseguridad.

Figura 9. Atardecer (1992)

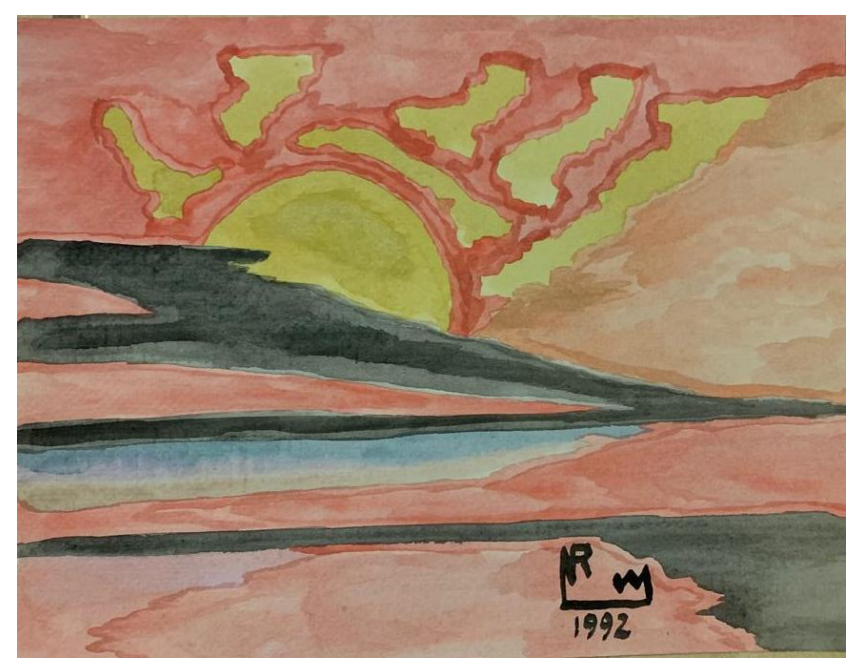

Fuente: Elaboración propia

En esta obra se destaca el color rojo (cielo), así como el amarillo, el negro y el azul. Tomando al color rojo como base, combinado con el amarillo, demuestra una actividad expansiva debido al gusto de la realización de la misma acción que va siempre dirigida a lo nuevo, a lo que aún está por descubrirse. La combinación del rojo y el negro puede significar un deseo exagerado o dramatización. Aquí el deseo normal se hace compulsivo y se refuerza. La combinación del rojo y el azul pueden indicar un espíritu emprendedor cooperativo para la realización sentimental, donde la actividad que se realice se presupone que llevará a la armonía. 

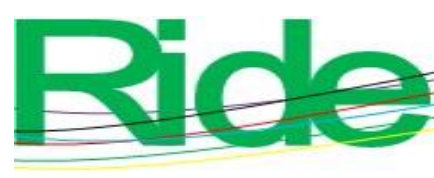

Revista Iberoamericana para la Investigación y el Desarrollo Educativo ISSN $2007-7467$

Figura 10. Amanecer (1992)

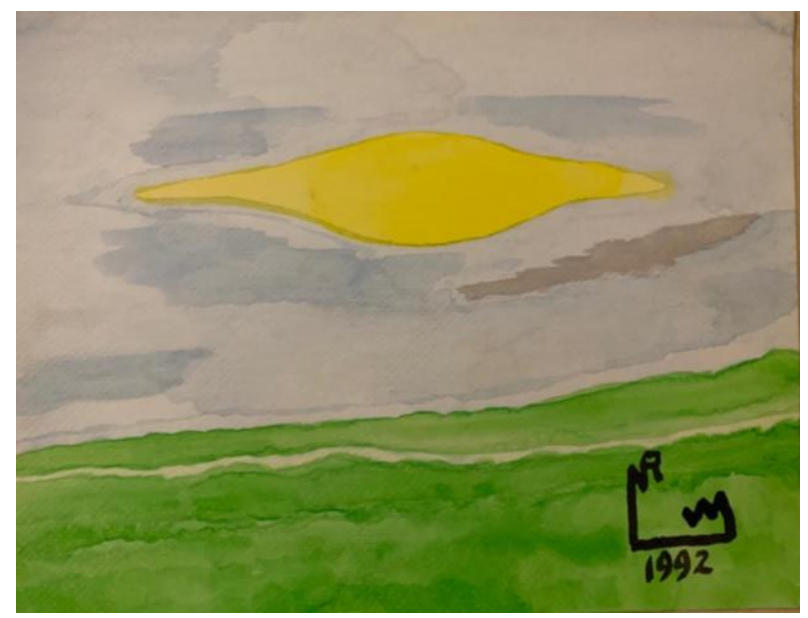

Fuente: Elaboración propia

En esta décima obra se observa especialmente la utilización de un tono azul (cielo), seguido del verde (montañas), el amarillo (sol) y el gris (una parte del cielo). Al tomar como base el color azul, combinado con el verde, puede indicar una intervención discriminativa o técnica libre, donde el sentimentalismo y la comprensión congruente trasladan a un aumento de la autoestima. Asimismo, el azul en combinación con el amarillo sugiere una sumisión sentimental o asistencia encaminada al grupo social donde la aspiración tanto de comprender como de ser comprendido y el anhelo del enemigo lo trasladan a una conducta que tiene como finalidad agradar el afecto de los demás. La combinación del azul con el gris señala un intervalo de tranquilidad o periodo de recuperación.

Figura 11. Montañas (1994)

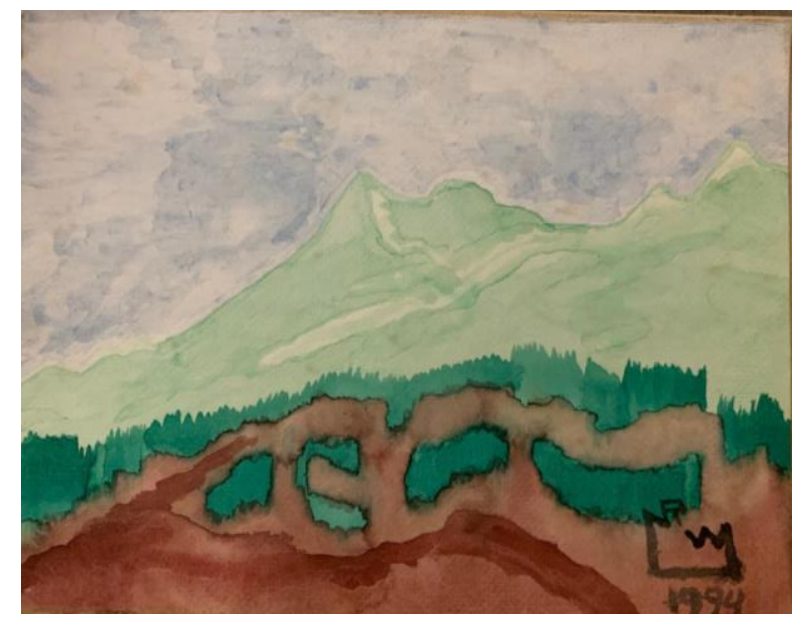

Fuente: Elaboración propia 


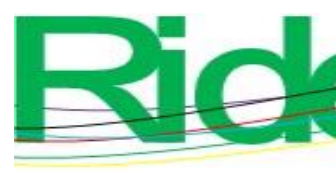

Revista Iberoamericana para la Investigación y el Desarrollo Educativo ISSN $2007-7467$

En esta última pintura predomina el verde (montañas y bosque), seguido por el azul (cielo) y el café (tierra). La combinación del verde y el azul muestra un grado alto de control discriminativo o procedimiento independiente, donde la exactitud, la razón y la necesidad de demostrar que se está en lo cierto prevalecen sobre la comprensión; por otro lado, la combinación del verde y el café puede indicar un requerimiento de alivio físico o insistencia en el bienestar.

\section{Discusión}

En el análisis del aspecto educativo-artístico de Claudio Vásquez a través de la psicología del color en once pinturas de su creación en el periodo de 1987 a 1994 tiene una particular esencia reflejada en sus pinturas que llevan al observador a un universo real, donde está realizado por la creatividad, la plasticidad, la estética y la originalidad que se convierte en virtud, porque es el que lleva el pincel a los profundos lugares del óleo y la acuarela. Su indagación se envuelve con sus reminiscencias, con la observación de masas de minerales, de constituciones rocosas, de cuerpos sólidos, líquidos y gases, así como con la forma en que esos componentes generales recorren sus pinturas, representándose de imágenes como el mejor método de interpretar la realidad del paisaje (Rivera, 2000). Las pinturas se reúnen en combate, calor y color que se mezclan en revuelos de luz y se nutren de aire (GómezAguiñaga, 2006).

\section{Conclusión}

En la influencia de las once pinturas analizadas en este trabajo sobresalen los colores verde y azul, lo que muestra aspectos educativos de Claudio Vásquez que se asocian con una adecuada sensibilidad y comprensión, lo cual influye en una autoestima alta. Asimismo, tiende a buscar cosas nuevas que le den satisfacción, pero que no traigan consigo incomodidad o perturbación en lo corporal.

Es importante aquí resaltar que esto está determinado por el contexto específico de esos años, marcado por acontecimientos que le pudieron suceder, por sus experiencias personales, así como por los sentimientos y emociones experimentadas. Por ende, es indispensable entender esta interpretación como algo "superficial" (hasta cierto punto), ya 


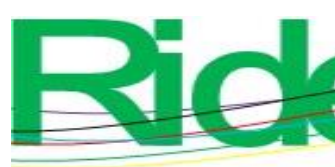

Revista Iberoamericana para la Investigación y el Desarrollo Educativo ISSN $2007-7467$

que no es un reflejo exacto de sus rasgos educativos, sino una deducción establecida al conjugar un binomio olvidado: la pintura y la generación del conocimiento.

\section{Futuras líneas de investigación}

Las siguientes pueden ser algunas futuras líneas de investigación:

- Estudios en aulas de clases de primaria, secundaria, preparatoria y universidad sobre aspectos educativos artísticos de los estudiantes.

- Estudios locales en centros de estudios educativos sobre los efectos de las pandemias y pospandemias con sus casos de resiliencia en la realización de aspectos educativos artísticos de los estudiantes.

\section{Referencias}

Acha, J. (1988). La apreciación artística y sus efectos. México: Trillas.

Adorno, T. W. (2004). Teoría estética. Madrid: Ediciones Akal, S. A.

Aguirre, L. (2006). Estudio comparativo entre el test abreviado y el test completo de los colores. Límite, Revista Interdisciplinaria de Filosofía y Psicología, 1(14), 159-174.

Baldessari, J. (2013). More tan you wanted to know about John Baldessari. Zurich: Ed. JRP Ringer.

Benítez, M. (2009). Narcotráfico e intervención en Colombia 1980-2000. Bogotá: Pontificia Universidad Javeriana.

Berni, A. (1971). Escritos y papeles privados. México, D. F.: Temas Grupo Editorial.

Botetano, C. (2014). La teoría de los hemisferios cerebrales y el método botetano.

Bustos, M. y Devoto, C. (2008). Estudio exploratorio-descriptivo de los indicadores de depresión y burnout del test de Lüscher en postulantes al cargo de Supervisor Santiago de Chile: Técnico Pedagógico del Ministerio de Educación. Universidad de Chile.

Cotes, A. M. (27 de enero de 2018). La importancia de la educación en el arte. Palabra Maestra. Recuperado de https://compartirpalabramaestra.org/blog/la-importanciadel-arte-en-la-educacion

Foucault, M. (2017). Obras esenciales. Barcelona: Paidós.

Frankl, V. (1991). El hombre en busca de sentido. Barcelona: Editorial Herder. 

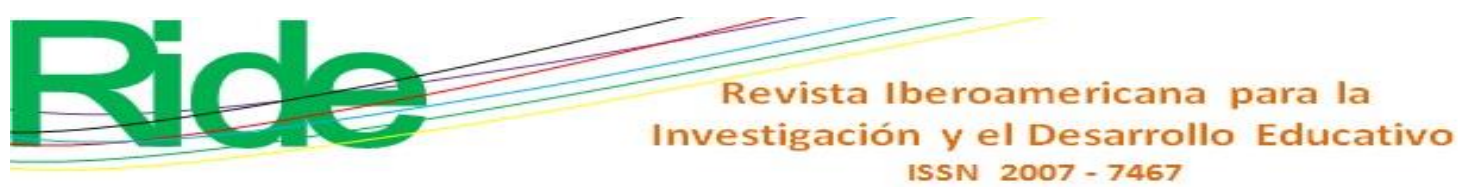

García Morales, C. (2012). ¿Qué puede aportar el arte a la educación?: el arte como estrategia para una educación inclusiva. ASRI: Arte y Sociedad. Revista de Investigación, (1), 5-12.

Gardner, H. (1993). La mente no escolarizada. España: Paidós.

Gómez-Aguiñaga, C. (2006). Filosofía de vida que desarrolla nuevos códigos ecológicos. Puerto Vallarta: Tribuna de la Bahía.

Gómez, C. (2006). Filosofía de vida que desarrolla nuevos códigos ecológicos. Puerto Vallarta: Tribuna de la Bahía.

Gómez, R. (2016). El color en la psicología (trabajo final de grado). Andalucía, España: Universidad de Jaén. Facultad de Humanidades y Ciencias de la Educación.

Jiménez, J. (2002). Teoría del arte. Madrid: Editorial Tecnos.

Lüscher, M. (1982). Test de los colores. Madrid: Editorial Paidós Ibérica.

Miño, A. (2011). Técnicas proyectivas para selección de personal. Test de Lüscher. Santiago de Chile: Universidad de Santiago de Chile.

Ortiz, L. (2004). Orgullo universitario. Guadalajara: Gaceta Universitaria.

Pérez Carreño, F. (1997). Revista de libros. Recuperado de https://www.revistadelibros.com/debates/

Rideal, L. (2014). Cómo leer pinturas, una guía sobre sus significados y métodos. Madrid, España: H. Blume.

Rivera A. (2000). Paisajes felices. Pereira: El Diario del Oton

Rodríguez, A. (20 de diciembre de 2017). Recibirá el doctorado Honoris Causa Claudio Rafael Vásquez Martínez. NotiVallarta. Recuperado de http://notivallarta.com/2017/12/20/recibira-el-doctorado-honoris-causa-claudiorafael-vasquez-martinez/

Vásquez, C. (1999). Evocación al paisaje. Pereira: Editorial Papiro.

Vásquez, C. (2000). Retrospectiva del arte de la pintura sobre la arquitectura paisajística. Pereira: Editorial Papiro. 


\begin{tabular}{|c|c|}
\hline Rol de Contribución & Autor (es) \\
\hline Conceptualización & $\begin{array}{l}\text { Claudio Rafael Vásquez Martínez, igual, Felipe Anastacio } \\
\text { González González, igual }\end{array}$ \\
\hline Metodología & $\begin{array}{l}\text { Claudio Rafael Vásquez Martínez, igual, Felipe Anastacio } \\
\text { González González, igual }\end{array}$ \\
\hline Software & $\begin{array}{l}\text { Claudio Rafael Vásquez Martínez, igual, Felipe Anastacio } \\
\text { González González, igual }\end{array}$ \\
\hline Validación & $\begin{array}{l}\text { Claudio Rafael Vásquez Martínez, igual, Felipe Anastacio } \\
\text { González González, igual }\end{array}$ \\
\hline Análisis Formal & $\begin{array}{l}\text { Claudio Rafael Vásquez Martínez, igual, Felipe Anastacio } \\
\text { González González, igual }\end{array}$ \\
\hline Investigación & $\begin{array}{l}\text { Claudio Rafael Vásquez Martínez, igual, Felipe Anastacio } \\
\text { González González, igual }\end{array}$ \\
\hline Recursos & $\begin{array}{l}\text { Claudio Rafael Vásquez Martínez, igual, Felipe Anastacio } \\
\text { González González, igual }\end{array}$ \\
\hline Curación de datos & $\begin{array}{l}\text { Claudio Rafael Vásquez Martínez, igual, Felipe Anastacio } \\
\text { González González, igual }\end{array}$ \\
\hline $\begin{array}{l}\text { Escritura - Preparación del } \\
\text { borrador original }\end{array}$ & $\begin{array}{l}\text { Claudio Rafael Vásquez Martínez, igual, Felipe Anastacio } \\
\text { González González, igual }\end{array}$ \\
\hline $\begin{array}{l}\text { Escritura - Revisión y } \\
\text { edición }\end{array}$ & $\begin{array}{l}\text { Claudio Rafael Vásquez Martínez, igual, Felipe Anastacio } \\
\text { González González, igual }\end{array}$ \\
\hline Visualización & $\begin{array}{l}\text { Claudio Rafael Vásquez Martínez, igual, Felipe Anastacio } \\
\text { González González, igual }\end{array}$ \\
\hline Supervisión & $\begin{array}{l}\text { Claudio Rafael Vásquez Martínez, igual, Felipe Anastacio } \\
\text { González González, igual }\end{array}$ \\
\hline $\begin{array}{l}\text { Administración } \\
\text { Proyectos }\end{array}$ & $\begin{array}{l}\text { Claudio Rafael Vásquez Martínez, igual, Felipe Anastacio } \\
\text { González González, igual }\end{array}$ \\
\hline Adquisición de fondos & $\begin{array}{l}\text { Claudio Rafael Vásquez Martínez, igual, Felipe Anastacio } \\
\text { González González, igual }\end{array}$ \\
\hline
\end{tabular}

